\title{
PERIOPERATIVE EFFECTS OF ALPHA-STAT VERSUS PH-STAT STRATEGIES FOR DEEP HYPOTHERMIC CARDIOPULMONARY BYPASS IN INFANTS
}

Adre J. du Plessis, MBChB, MPH

Richard A. Jonas, MD

David Wypij, PhD

Paul R. Hickey, MD

James Riviello, MD

David L. Wessel, MD

Stephen J. Roth, MD, MPH

Frederick A. Burrows, MD

Gene Walter, REEGT

David M. Farrell, MA, CCP

Amy Z. Walsh, RN

Christine A. Plumb, RN, MSN

Pedro del Nido, MD

Redmond P. Burke, MD

Aldo R. Castaneda, MD

John E. Mayer, Jr., MD

Jane W. Newburger, MD, MPH
Objectives: In a randomized, single-center trial, we compared perioperative outcomes in infants undergoing cardiac operations after use of the alphastat versus pH-stat strategy during deep hypothermic cardiopulmonary bypass. Methods: Admission criteria included reparative cardiac surgery, age less than 9 months, birth weight $2.25 \mathrm{~kg}$ or more, and absence of associated congenital or acquired extracardiac disorders. Results: Among the 182 infants in the study, diagnoses included D-transposition of the great arteries $(n=92)$, tetralogy of Fallot $(n=50)$, tetralogy of Fallot with pulmonary atresia $(n=6)$, ventricular septal defect $(n=20)$, truncus arteriosus $(n=8)$, complete atrioventricular canal $(n=4)$, and total anomalous pulmonary venous return $(n=2)$. Ninety patients were assigned to alpha-stat and 92 to $\mathrm{pH}$-stat strategy. Early death occurred in four infants $(2 \%)$, all in the alpha-stat group $(p=0.058)$. Postoperative electroencephalographic seizures occurred in five of 57 patients $(9 \%)$ assigned to alpha-stat and one of 59 patients $(2 \%)$ assigned to $\mathrm{pH}$-stat strategy $(p=0.11)$. Clinical seizures occurred in four infants in the alpha-stat group (4\%) and two infants in the pH-stat group (2\%) $(p=0.44)$. First electroencephalographic activity returned sooner among infants randomized to $\mathrm{pH}$-stat strategy $(p=0.03)$. Within the homogeneous D-transposition subgroup, those assigned to $\mathrm{pH}$-stat tended to have a higher cardiac index despite a lower requirement for inotropic agents; less frequent postoperative acidosis $(p=0.02)$ and hypotension $(p=0.05)$; and shorter duration of mechanical ventilation $(p=0.01)$ and intensive care unit stay $(p=0.01)$. Conclusions: Use of the pH-stat strategy in infants undergoing deep hypothermic cardiopulmonary bypass was associated with lower postoperative morbidity, shorter recovery time to first electroencephalographic activity, and, in patients with D-transposition, shorter duration of intubation and intensive care unit stay. These data challenge the notion that alpha-stat management is a superior strategy for organ protection during reparative operations in infants using deep hypothermic cardiopulmonary bypass. (J Thorac Cardiovasc Surg 1997;114:991-1001)
D uring hypothermic cardiopulmonary bypass in infants, the optimal approach to intraoperative acid-base management remains controversial, ${ }^{1,2}$

From the Departments of Cardiology (D.L.W., S.J.R., A.Z.W., C.A.P., J.W.N.), Cardiovascular Surgery (R.A.J., D.M.F., P.D.N., R.P.B., A.R.C., J.E.M.), Anesthesiology (P.R.H., F.B.), Neurology (A.J.D.P., J.R., G.W.), Children's Hospital, and the Departments of Pediatrics, Surgery, and Neurology, Harvard Medical School; and the Department of Biostatistics (D.W.), Harvard School of Public Health, Boston, Mass.

Supported by grants NS32570, RR02172, and K08-MNS01721 from the National Institutes of Health, the Kobren Fund, and the William Randolph Hearst Foundation. particularly with regard to postoperative neurologic outcome. Both the alkalotic alpha-stat strategy and the hypercarbic $\mathrm{pH}$-stat strategy have potential ad-

Read at the Seventy-seventh Annual Meeting of The American Association for Thoracic Surgery, Washington, D.C., May 4-7, 1997.

Received for publication May 7, 1997; revisions requested June 16, 1997; revisions received July 30, 1997; accepted for publication July 31, 1997.

Address for reprints: Richard A. Jonas, MD, Department of Cardiovascular Surgery, Children's Hospital, 300 Longwood Ave., Boston, MA 02115.

Copyright (C) 1997 by Mosby-Year Book, Inc.

$0022-5223 / 97 \$ 5.00+0 \quad \mathbf{1 2 / 6 / 8 5 2 7 6}$ 
vantages for maintaining cellular homeostasis and energy balance during periods of decreased cerebral perfusion. ${ }^{3-6}$

Studies in adults undergoing cardiac operations have suggested that the alpha-stat technique improves postoperative neuropsychologic outcome..$^{6-8}$ On the basis of these studies and certain theoretical considerations, the alpha-stat strategy has gained widespread support among pediatric cardiac surgeons and perfusionists, despite the lack of prospective data in infants. However, both operative techniques and mechanisms of brain injury differ significantly between adults and infants undergoing cardiac surgery. Intraoperative cerebral injury in adults is related to atheromatous emboli or to fixed cerebrovascular stenoses. In infants, brain injury results most commonly from global hypoperfusion during periods of decreased or arrested systemic blood flow. Finally, in contrast to the moderate hypothermia used in adults, the deep hypothermia used in infant cardiac surgery causes a more pronounced divergence between the two $\mathrm{pH}$ management strategies and their physiologic effects.

As a result of these concerns, retrospective analyses were performed in children ${ }^{9,10}$ and the two techniques were compared in a neonatal piglet mode ${ }^{11,12}$ at our institution. Both these approaches supported a superior neuroprotective role for the pH-stat strategy during deep hypothermic cardiac surgery. In view of these findings, the need for prospective data in infants became increasingly obvious. The present prospective, randomized, singlecenter trial compared neurologic and cardiovascular outcomes in infants randomized to either the alphastat or $\mathrm{pH}$-stat strategy during deep hypothermic cardiac surgery.

\section{Methods}

Enrollment of patients. We enrolled patients between July 1992 and July 1996 at Children's Hospital, Boston. Of 216 eligible infants for whom informed consent was requested, participation was declined in $26(12 \%)$. Of the 190 patients enrolled, eight $(4 \%)$ were excluded post hoc because their operation was not performed under deep hypothermia (tympanic temperature $\leq 18^{\circ} \mathrm{C}$ ). The remaining 182 patients underwent reparative operations according to the study protocol and form our study population. The criteria for eligibility included reparative heart surgery at age less than 9 months for diagnoses including D-transposition of the great arteries (D-TGA) with intact ventricular septum (IVS) or ventricular septal defect (VSD), tetralogy of Fallot (TOF), TOF with pulmonary atresia, VSD, complete common atrioventricular canal defect, truncus arteriosus, or total anomalous pul- monary venous return. Exclusion criteria included birth weight less than $2.25 \mathrm{~kg}$, associated congenital or acquired extracardiac disorders of greater than minor severity, and previous surgery. Informed consent was obtained from the parents of all infants according to the guidelines of the Committee on Clinical Investigation of the Children's Hospital.

Study design. Participating infants were randomly assigned to receive a $\mathrm{pH}$ management strategy of either pH-stat or alpha-stat, with stratification according to surgeon, diagnosis, and age group ( $<1$ month, 1 to 4 months, and 5 to 9 months). Randomization schemes were developed with a permuted blocks design; the method of support was assigned immediately before the operation. Outcome variables were obtained by investigators who were blinded to each patient's treatment assignment. Surgeons and anesthesiologists were kept unaware of the interim results during the study.

Extracorporeal perfusion and anesthesia methods. Perfusion methods were identical in both $\mathrm{pH}$ management groups, except as described herein. After induction of anesthesia and placement of an arterial line, surface cooling was begun with a low ambient room temperature, a cooling mattress, and ice packs to the head. An arterial cannula was placed in the ascending aorta. Venous cannulation was accomplished by the placement of a single right atrial cannula or by bicaval cannulation of the inferior and superior venae cavae. Cardiopulmonary bypass and core cooling were begun as soon as the cannulas were in place. During the induction of hypothermia, there is a natural tendency for blood to become more alkalotic. With no intervention, this constitutes the alpha-stat strategy. For the $\mathrm{pH}$-stat strategy, the patient's $\mathrm{pH}$ as read from a blood gas analyzer at $37^{\circ} \mathrm{C}$ was adjusted to be 7.40 at the patient's tympanic membrane temperature with the use of a nomogram. This necessitated the addition of carbon dioxide to the ventilating gas of the oxygenator during cooling and low-flow bypass. At the start of rewarming, alpha-stat management was instituted for all patients. The blood flow rate during cooling and rewarming was $150 \mathrm{ml} / \mathrm{kg}$ per minute; during low-flow bypass, the flow rate was $50 \mathrm{ml} / \mathrm{kg}$ per minute. Patients were rewarmed to a rectal temperature of at least $35^{\circ} \mathrm{C}$ before the cessation of bypass.

Anesthetic management was performed according to a standardized protocol. The intraoperative administration of intravenous fluids was limited to lactated Ringer's solution ( 10 to $20 \mathrm{ml} / \mathrm{kg}$ per hour) unless the blood glucose level was lower than $50 \mathrm{mg} / \mathrm{dl}$. Anesthesia was induced with fentanyl $(50 \mu \mathrm{g} / \mathrm{kg})$ and pancuronium (100 $\mu \mathrm{g} / \mathrm{kg}$ ). Plasma levels of fentanyl and pancuronium were maintained during bypass with an additional $25 \mu \mathrm{g} / \mathrm{kg}$ of fentanyl and $100 \mu \mathrm{g} / \mathrm{kg}$ of pancuronium. All patients received methylprednisolone $(30 \mathrm{mg} / \mathrm{kg})$ at the onset of bypass. During rewarming, an additional $25 \mu \mathrm{g} / \mathrm{kg}$ of fentanyl and $100 \mu \mathrm{g} / \mathrm{kg}$ of pancuronium were administered.

Postoperative hemodynamic data collection. Cardiac output was determined by the thermodilution technique beginning 3 hours after removal of the aortic crossclamp and repeated at 3 -hour intervals during the first 24 hours after the operation. The pulmonary artery catheter was a 
Volume 114, Number 6

$3.5 \mathrm{~F}$ double-lumen catheter equipped with a radiopaque thermistor. Triplicate measurements of cardiac output were made over 1 to 2 minutes with $1 \mathrm{ml}$ injections of iced $5 \%$ dextrose in water into the right atrial line. Cardiac index was calculated by dividing the average cardiac output by body surface area. The doses of inotropic, chronotropic, and afterload-reducing agents were recorded at the time of each set of cardiac output measurements. Total inotropic dose was calculated by adding the doses of dopamine and dobutamine in micrograms per kilogram per minute and assigning an arbitrary inotropic dose of $10 \mu \mathrm{g} / \mathrm{kg}$ per minute for each $0.1 \mu \mathrm{g} / \mathrm{kg}$ per minute of epinephrine.

Neurologic methods. Clinical seizures were recorded by the bedside nurses or physicians caring for the infant. Definite clinical seizures were defined as the occurrence of a single or recurrent motor event, with tonic or clonic movements of an extremity or cranial muscle that were associated with an alteration of consciousness and were not interruptible by manipulation of the body part involved. Isolated abnormalities involving apnea, tachycardia, eye movements, sucking movements, or tongue movements were considered indeterminate and were included under the classification of possible seizures.

The electroencephalogram (EEG) was monitored continuously for at least 2 hours before the operation, during the operation, and for 48 hours after the operation by video EEG (Telefactor, Modac, West Conshohocken, Pa.). The EEG data were interpreted by one of two pediatric electroencephalographers according to predetermined criteria. EEG seizures (ictal activity) were defined as rhythmic paroxysmal activity of at least $10 \mathrm{sec}-$ onds' duration. Reappearance latency to first activity was assessed as the time in minutes from the onset of rewarming until reappearance of EEG activity greater than 15 $\mathrm{mV}$ amplitude persisting for longer than 3 seconds in any lead.

Neurologic examination was performed by a pediatric neurologist according to a uniform, predetermined protocol before the operation and again before the patient's discharge from the hospital. Abnormalities on neurologic examination were classified according to specific type, including head circumference, mental status, special senses, cranial nerve motor function (oculomotor, facial, and oromotor function), and peripheral motor function (weakness that was global or focal; abnormalities of tone or tendon reflexes unassociated with weakness). Patients were classified as having an abnormal neurologic examination if any summary item included a definite abnormality.

Statistical analysis. Intention-to-treat analyses were used to compare infants assigned to the alpha-stat strategy and those assigned to the pH-stat strategy. Primary outcomes were EEG recovery time to first activity and the occurrence of clinical and EEG seizures. Secondary outcomes included duration of intubation, stay in the intensive care unit, and hospital stay; postoperative events; and postoperative cardiac index. Subgroup analyses for patients with D-TGA were performed because they comprised a large homogeneous population in which differences between strategies were expected to be most apparent.
Table I. Preoperative characteristics according to treatment group

\begin{tabular}{lcc}
\hline & $\begin{array}{c}\text { Alpha-stat } \\
(n=90)\end{array}$ & $\begin{array}{c}p H \text {-stat } \\
(n=92)\end{array}$ \\
\hline Birth weight (kg), mean \pm SD & $3.33 \pm .57$ & $3.38 \pm .55$ \\
Age at operation (days), median & $9(1-273)$ & $7(1-222)$ \\
$\quad$ (range) & & \\
Diagnoses, n (\%) & & \\
D-TGA, IVS & $29(32)$ & $37(40)$ \\
D-TGA, VSD & $15(17)$ & $11(12)$ \\
TOF & $25(28)$ & $25(27)$ \\
TOF, PA & $3(3)$ & $3(3)$ \\
VSD & $12(13)$ & $8(9)$ \\
Complete common AV canal & $2(2)$ & $2(2)$ \\
Truncus arteriorsus & $3(3)$ & $5(5)$ \\
TAPVR & $1(1)$ & $1(1)$ \\
\hline
\end{tabular}

$D$-TGA, dextro-transposition of the great arteries; $I S$, intact ventricular septum; VSD, ventricular septal defect; $T O F$, tetralogy of Fallot; $A V$, atrioventricular; $T A P V R$, total anomalous pulmonary venous return; $S D$, standard deviation.

Fisher's exact tests were used to analyze dichotomous outcome variables. Linear regression was used to analyze continuous outcome variables. If the distribution of a continuous outcome was skewed, Wilcoxon rank-sum tests were instead used to compare treatment groups. The proportional hazards regression model was used to analyze reappearance latency to first EEG activity. Analyses of continuous variables using linear regression or the proportional hazards regression model adjust for diagnostic group. All $p$ values are two-tailed. Statistical analyses were performed with SAS (SAS Institute, Inc., Cary, N.C.).

\section{Results}

Comparability of treatment groups. Among the 182 study infants, $116(64 \%)$ were male. Table I summarizes the demographic characteristics of infants according to $\mathrm{pH}$ strategy. The most common diagnoses were D-TGA $(92,51 \%)$, TOF without or with pulmonary atresia $(56,31 \%)$, and VSD $(20$, $11 \%)$. As expected, the mean age at operation was younger in the D-TGA subgroup $(6 \pm 5$ days, mean \pm standard deviation), than in the TOF subgroup ( $85 \pm 72$ days) or the VSD subgroup (135 \pm 62 days). Treatment assignments were balanced within the randomization strata of diagnostic group, surgeon, and age. Infants who were randomly assigned to the two $\mathrm{pH}$ strategies were similar at enrollment with respect to preoperative history, except that preoperative suspected or definite sepsis was more common among infants subsequently randomized to the $\mathrm{pH}$-stat strategy ( $24 \%$ vs $11 \%$, $\mathrm{pH}$-stat vs alpha-stat, $p=0.03$ ). The treatment groups did not differ significantly in the preoperative incidence of abnormalities on neurologic examination or electroen- 
Table II. Preoperative neurologic status according to treatment group

\begin{tabular}{lcc}
\hline & Alpha-stat & pH-stat \\
\hline & No. with abnormality/ \\
total n $(\%)$
\end{tabular}

*Among those in whom item could be assessed.

cephalogram (Table II). One infant assigned to the alpha-stat group had a preoperative seizure.

Intraoperative perfusion variables. The durations of circulatory arrest, total bypass, total support, and crossclamp were similar between the treatment groups (Table III). Neonates in the D-TGA diagnosis group, all undergoing the arterial switch operation, had the longest mean total support and crossclamp times (Table IV). The randomization was successful in achieving significant differences between the treatment groups with regard to $\mathrm{pH}$ during hypothermic bypass; $\mathrm{pH}$ was significantly lower in the $\mathrm{pH}$-stat than the alpha-stat group from its measurement 5 minutes after initiation of core cooling through cessation of bypass (Fig. 1, $A$ ). Similarly, carbon dioxide tension was significantly higher in infants randomized to $\mathrm{pH}$-stat through this time period (Fig. 1, B). Arterial oxygen tension tended to be lower among infants in the pH-stat group during bypass, reaching a statistically significant difference at time points 5 minutes after resumption of bypass and when warming to $25^{\circ} \mathrm{C}$ (Fig. $1, C)$. Of interest, however, this trend reversed after cessation of bypass, such that the oxygen tension measured 10 minutes after cessation of bypass tended to be higher among infants in the pH-stat group than in those treated with the alpha-stat strategy $(253 \pm 151 \mathrm{~mm} \mathrm{Hg}$ vs $214 \pm 152 \mathrm{~mm} \mathrm{Hg}$, $p=0.053)$.

Although perfusion pressure (i.e., mean arterial pressure) was comparable in the two treatment
Table III. Intraoperative data according to treatment group

\begin{tabular}{|c|c|c|c|}
\hline Variable & $\begin{array}{c}\text { Alpha-stat } \\
(\dot{n}=90)\end{array}$ & $\begin{array}{c}\text { pH-stat } \\
(n=92)\end{array}$ & $\begin{array}{c}p \\
\text { Value* }\end{array}$ \\
\hline $\begin{array}{l}\text { No. }(\%) \text { of subjects with } \\
>30 \text { min of circulatory } \\
\text { arrest }\end{array}$ & $35(39)$ & $30(33)$ & 0.44 \\
\hline \multirow[t]{2}{*}{$\begin{array}{l}\text { No. }(\%) \text { of subjects with } \\
>45 \text { min of circulatory } \\
\text { arrest }\end{array}$} & $7(8)$ & $9(10)$ & 0.79 \\
\hline & \multicolumn{2}{|c|}{ Mean $\pm S D$} & \\
\hline Total support time (min) & $129 \pm 49$ & $124 \pm 39$ & 0.19 \\
\hline Total bypass time ( $\mathrm{min}$ ) & $107 \pm 50$ & $103 \pm 39$ & 0.30 \\
\hline Low-flow bypass ( $\mathrm{min}$ ) & $41 \pm 31$ & $41 \pm 29$ & 0.76 \\
\hline Circulatory arrest (min) & $22 \pm 16$ & $21 \pm 17$ & 0.56 \\
\hline Crossclamp time (min) & $67 \pm 23$ & $68 \pm 22$ & 0.97 \\
\hline Fluid balance $\dagger(\mathrm{ml})$ & $607 \pm 273$ & $537 \pm 260$ & 0.10 \\
\hline
\end{tabular}

*Fisher's exact $p$ value for the effect of treatment for dichotomous outcomes, and linear regression $p$ value for the effect of treatment, with adjustment for diagnostic group, for continuous outcomes.

†Input minus output.

groups during the cooling phase of bypass, these pressures tended to be lower among infants in the $\mathrm{pH}$-stat group just before the onset of total circulatory arrest $(p=0.07)$ and were significantly lower $(p<0.05)$ at consecutive study time points measured at resumption of bypass and when warming at $25^{\circ} \mathrm{C}$ and $32^{\circ} \mathrm{C}$ (Fig. $1 \mathrm{D}$ ). Infants assigned to the $\mathrm{pH}$-stat strategy tended to have a lower coldest tympanic membrane temperature during the operation than did the alpha-stat group $\left(14.8^{\circ} \pm 1.8^{\circ} \mathrm{C}\right.$ vs $\left.15.3^{\circ} \pm 1.5^{\circ} \mathrm{C}, p=0.052\right)$; otherwise, intraoperative temperatures were similar between the groups.

The serum sodium content was higher $(p<0.001)$ among patients in the $\mathrm{pH}$-stat group in consecutive time points from the onset of low-flow bypass or total circulatory arrest until reaching $25^{\circ} \mathrm{C}$, and was also higher $(p=0.03)$ at $32^{\circ} \mathrm{C}$. Throughout this same period, the serum $\mathrm{pH}$ was significantly lower in the $\mathrm{pH}$-stat group. After cessation of bypass, however, differences in serum sodium between groups did not achieve statistical significance. In a sample of 40 patients with D-TGA ( 20 in each treatment group), differences in intraoperative serum sodium concentration could not be attributed to disparate administration of sodium bicarbonate to the treatment groups. Intraoperative serum calcium concentration was lower in the alpha-stat group than in the $\mathrm{pH}$-stat group only when warming achieved $32^{\circ} \mathrm{C}$ $(1.18 \pm 0.23 \mathrm{mg} / \mathrm{dl}$ vs $1.26 \pm 0.22 \mathrm{mg} / \mathrm{dl}, p=0.01)$. There were no significant differences between groups in levels of intraoperative potassium. 
Table IV. Intraoperative data according to diagnostic group

\begin{tabular}{lcccc}
\multicolumn{1}{c}{ Variable } & $\begin{array}{c}D-T G A \\
(n=92)\end{array}$ & $\begin{array}{c}\text { TOF/other } \\
(n=66)\end{array}$ & $\begin{array}{c}\text { VSD/CAVC } \\
(n=24)\end{array}$ & $p$ Value* \\
\hline Total support time (min) & $154 \pm 40$ & $100 \pm 26$ & $95 \pm 26$ & $<0.001$ \\
Circulatory arrest (min) & $21 \pm 15$ & $26 \pm 17$ & $15 \pm 17$ & 0.02 \\
Crossclamp time (min) & $83 \pm 17$ & $51 \pm 15$ & $54 \pm 20$ & $<0.001$ \\
\hline
\end{tabular}

Values are mean \pm standard deviation. CAVC, common atrioventricular canal. For other abbreviations see Table I.

${ }^{*} F$-test $p$ value for the effect of diagnostic group from analysis of variance.

Postoperative course. Four of the 182 infants (2\%) died within 1 month of the operation, all infants with D-TGA (two with IVS and two with VSD) in the alpha-stat group ( $p=0.058$ ). Infants assigned to the alpha-stat group received greater inotropic support 9 hours after crossclamp removal ( $p=0.04$ ); otherwise the two treatment groups did not differ significantly with respect to cardiac index and inotropic support in the first 24 hours after the operation (Fig. 2, A). Within the homogeneous D-TGA subgroup, infants in the $\mathrm{pH}$-stat group tended to have higher cardiac indices and lower inotropic support at most time points (Fig. 2, B), although these differences did not achieve statistical significance.

Medical events in the treatment groups are summarized in Table V. Compared with infants randomized to $\mathrm{pH}$-stat, those in the alpha-stat group tended to have more frequent hypocalcemia $(p=0.056)$, an effect most pronounced within the TOF subgroup (53\% vs $26 \%, p=0.04)$. Infants randomized to the alpha-stat strategy also tended to have more frequent coagulopathy $(p=0.056)$ and chest tube placement $(p=0.08)$. In the homogeneous D-TGA subgroup, a greater proportion of patients in the alpha-stat group had a hypotensive episode ( $45 \%$ vs $25 \%, p=0.05)$, acidosis $(11 \%$ vs $0 \%, p=0.02)$, and anemia $(18 \%$ vs $4 \%, p=0.04)$. No postoperative event was significantly more common in infants in the $\mathrm{pH}$-stat group, either in the combined diagnosis groups or in any diagnostic subgroup.

In the combined diagnosis groups, median duration of intubation, stay in the intensive care unit, and postoperative hospital stay were slightly shorter in the $\mathrm{pH}$-stat group, but differences did not achieve statistical significance. Within the D-TGA subgroup, patients who were randomized to the $\mathrm{pH}$-stat strategy, compared with those in the alpha-stat group, had significantly shorter duration of intubation (median 2.8 days vs 3.1 days, $p=0.01$ ) and significantly fewer days in the intensive care unit (median 4 days vs 5 days, $p=0.01$ ). Although hospital stay was also somewhat shorter among infants in the $\mathrm{pH}$-stat group who had D-TGA (median 8 days vs 9 days), this difference did not achieve statistical significance. There were no significant differences or trends in the comparison of the alpha-stat and $\mathrm{pH}$-stat groups in these variables among infants in the TOF or VSD subgroups.

Neurologic outcomes. Definite clinical seizures occurred in four infants (4\%) in the alpha-stat group and two infants $(2 \%)$ in the pH-stat group (Table $\mathrm{VI})$. One of the infants with seizures in the $\mathrm{pH}$-stat group was given a diagnosis of DiGeorge syndrome after hospital discharge, and one infant in the alpha-stat group who had postoperative seizures also had a seizure before the operation. Possible clinical seizures were suspected in an additional two infants in the alpha-stat group. These differençes did not achieve statistical significance. Clinical seizures were most common among infants in the D-TGA subgroup; in the alpha-stat group, definite seizures occurred in three (7\%) and suspected seizures in two infants $(4 \%)$; in the $\mathrm{pH}$-stat group, definite seizures occurred in one infant $(2 \%)$. Two additional patients in the TOF subgroup (one alpha-stat, $3 \%$; one $\mathrm{pH}$-stat, $3 \%$ ) had definite clinical seizures.

Epileptiform activity on continuous EEG monitoring during the first 48 hours after the operation tended to be more frequent among children assigned to the alpha-stat strategy than among those in the pH-stat group ( $9 \%$ vs $2 \%$, respectively, $p=$ 0.11). As with clinical seizures, most EEG seizures occurred in infants with D-TGA (three in the alphastat group and one in the $\mathrm{pH}$-stat group).

Infants assigned to the alpha-stat group, compared with the $\mathrm{pH}$-stat group, had longer time to first EEG activity (hazard ratio $=1.54,95 \%$ confidence interval, 1.03 to $2.30 ; p=0.03$ ).

Neurologic examination at the time of hospital discharge was classified as abnormal in two thirds of all patients, but the proportion classified as abnor- 

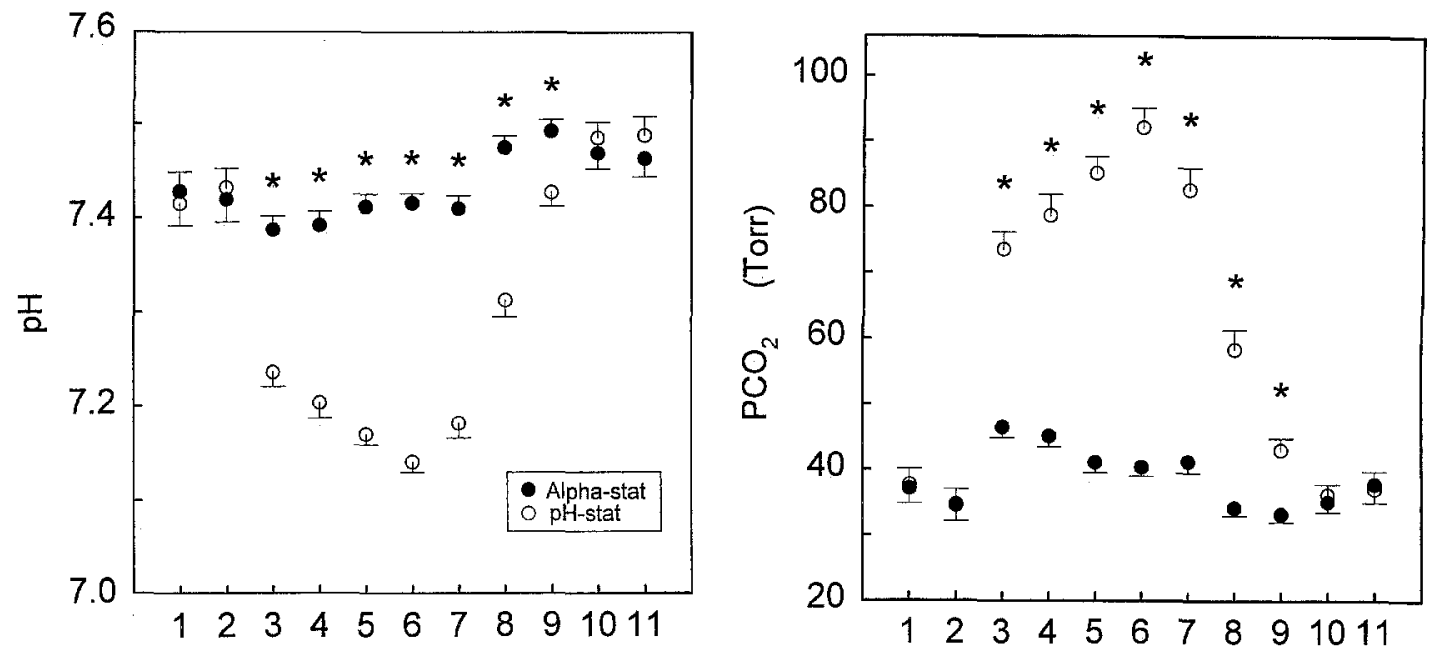

A

Perfusion Phase

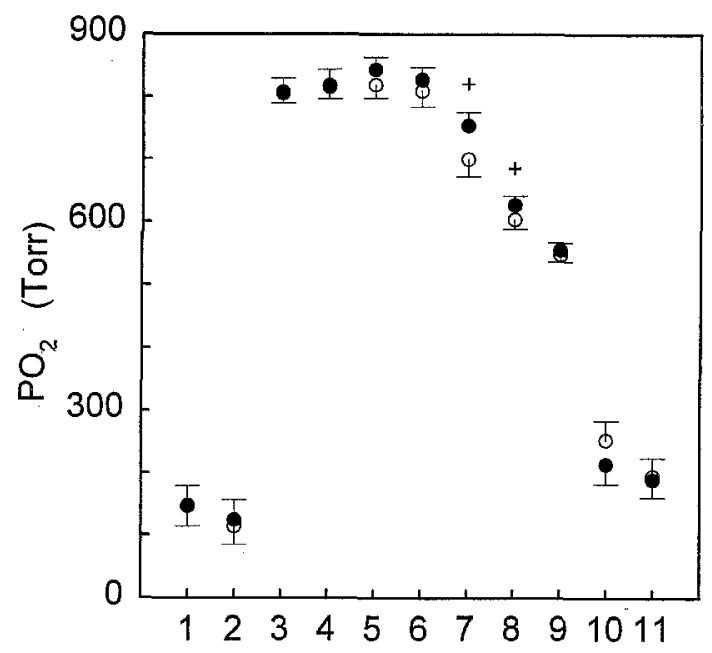

B

Perfusion Phase

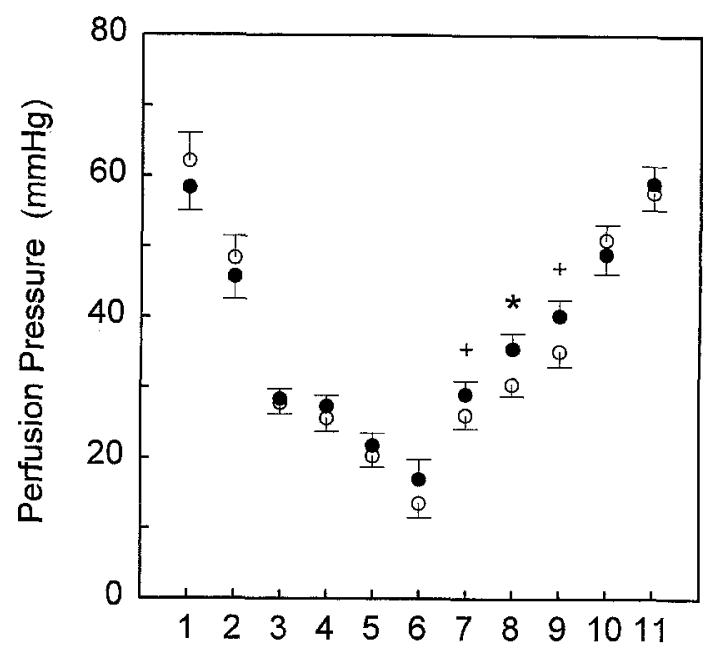

C

\section{Perfusion Phase}

Fig. 1. Plots showing serial measurements of $\mathrm{pH}(\mathrm{A})$, carbon dioxide tension $\left(\mathrm{PCO}_{2}\right)(\mathbf{B})$, oxygen tension $\left(\mathrm{PO}_{2}\right)(\mathrm{C})$, and perfusion pressure (D) according to treatment group and perfusion phase: $1=$ after induction; $2=$ heparin administered; $3=5$ minutes after commencement of cooling; $4=$ reaching $18^{\circ} \mathrm{C}$ rectal temperature; $5=$ onset of low-flow cardiopulmonary bypass; $6=$ onset of circulatory arrest; $7=5$ minutes after resumption of cardiopulmonary bypass; $8=$ reaching $25^{\circ} \mathrm{C}$ rectal temperature; $9=$ reaching $32^{\circ} \mathrm{C}$ rectal temperature; $10=10$ minutes after cessation of bypass; $11=1.5$ hours after crossclamp removal. Values are depicted as the mean and one side of each $95 \%$ confidence interval. Closed circles represent the alpha-stat group and open circles represent the $\mathrm{pH}$-stat group. Asterisks denote $p<0.001$ and plus signs denote $p<0.05$, adjusting for diagnostic group.

mal was similar in the alpha-stat and $\mathrm{pH}$-stat groups ( $71 \%$ vs $69 \%$, respectively). Of note, the abnormalities were usually subtle and would not have been noted in routine care by the patients' cardiologists or cardiovascular surgeons.

\section{Discussion}

In this prospective clinical trial of acid-base management during cardiac surgery in infants, randomization to the $\mathrm{pH}$-stat strategy was associated with generally better outcomes than was randomization 


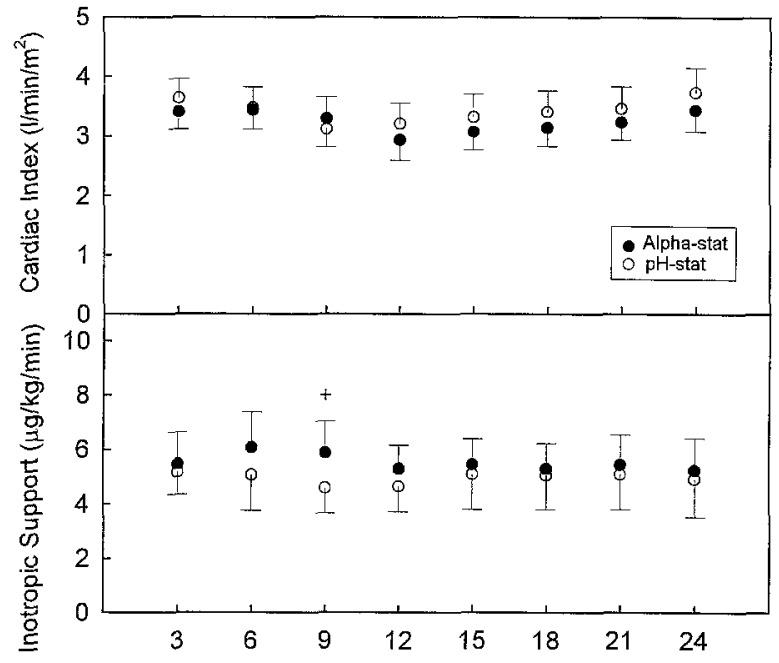

A Hours Following Cross-Clamp Removal

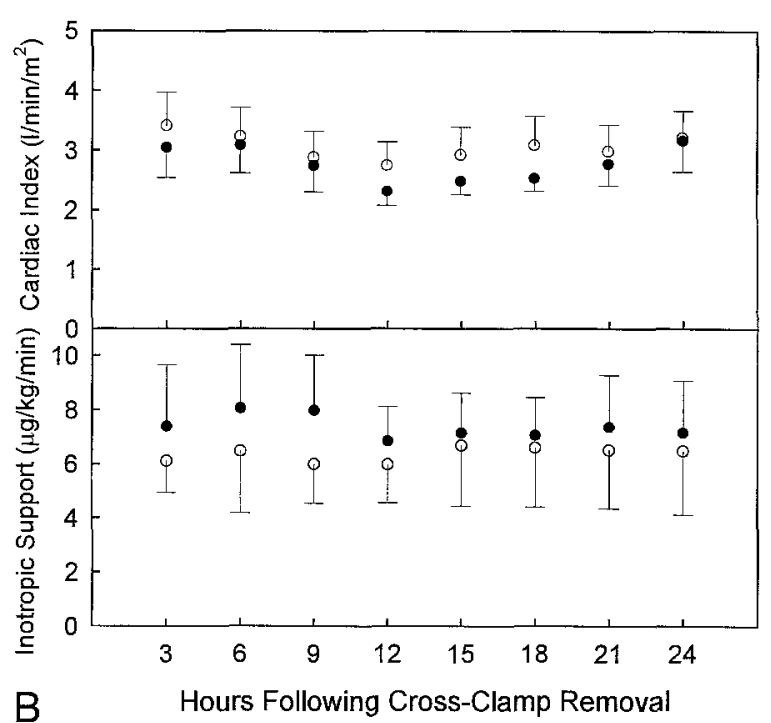

B

Fig. 2. Plots showing serial measurements of cardiac index (top) as determined by thermodilution techniques and total inotropic support (bottom) according to treatment group and hours after crossclamp removal. A, Data for all diagnoses. B, Data for patients with D-TGA only. Values are depicted as the mean and one side of the $95 \%$ confidence interval. Closed circles represent the alpha-stat group and open circles represent the $\mathrm{pH}$-stat group. Plus sign denotes $p<0.05$, adjusting for diagnostic group.

to the alpha-stat strategy. Infants assigned to the $\mathrm{pH}$-stat strategy had significantly shorter recovery time to first EEG activity and a tendency to fewer EEG seizures. In addition, infants in the $\mathrm{pH}$-stat group tended to have a lower incidence of postoperative homeostatic derangement, including hypocalcemia and coagulopathy. Analyses of the more homogeneous neonatal D-TGA subgroup were performed because this group had the longest crossclamp and total support times and hence were at risk for poor outcomes. Those assigned to $\mathrm{pH}$-stat tended to have higher cardiac index at 12, 15, and 18 hours despite a lower requirement for inotropic drugs, significantly less frequent postoperative acidosis and hypotension, and significantly shorter mechanical ventilation and intensive care unit stay. Early postoperative death occurred in four infants $(2 \%)$, all in the alpha-stat group.

The finding of worse neurologic outcomes in infants managed by the alpha-stat technique is supported by previous retrospective clinical studies. Children who had undergone the Senning procedure under alpha-stat conditions showed worse neurodevelopmental outcome than those managed by the $\mathrm{pH}$-stat technique, ${ }^{9}$ and another report noted a striking increase in postoperative choreoathetosis after the institution of the alpha-stat strategy. ${ }^{10}$ Previous prospective data for the immature brain have been derived only from animal studies. ${ }^{3,11-13}$ In the neonatal piglet, $\mathrm{pH}$-stat was associated with better preservation of cytochrome aa3 oxidation (an indicator of cellular oxygen delivery) ${ }^{12}$ and improved recovery of cerebral high-energy phosphates and intracellular $\mathrm{pH}$ during reperfusion. ${ }^{11}$

Prospective studies in adult cardiac surgery found either no difference ${ }^{14}$ or worse neuropsychologic outcome $^{6-8}$ after use of the pH-stat technique. These discrepant results between adults and infants may reflect different primary mechanisms of injury. First, the moderate hypothermia used in adult operations, compared with those performed with deep hypothermia in infants, will result in milder alkalosis and hence less carbon dioxide "correction" to achieve $\mathrm{pH}$-stat conditions. In adults, the relative vasodilation caused by $\mathrm{pH}$-stat techniques may increase cerebral delivery of embolic material or "steal" blood flow away from the poststenotic area. In contrast, brain injury during infant cardiac surgery is thought to result primarily from hypoperfusion during periods of low or no systemic blood flow. Under $\mathrm{pH}$-stat conditions, cerebral oxygen supply will be enhanced and use decreased. 
Table V. Postoperative events according to treatment group

\begin{tabular}{lccc}
\hline \multicolumn{1}{c}{ Event } & $\begin{array}{c}\text { Alpha-stat } \\
(n=90)\end{array}$ & $\begin{array}{c}p H \text {-stat } \\
(n=92)\end{array}$ & $\begin{array}{c}p \\
\text { Value }\end{array}$ \\
\hline \multicolumn{2}{c}{$n(\%)$} \\
Cardiac arrest & $3(3)$ & $1(1)$ & 0.37 \\
Hypotension & $23(26)$ & $15(16)$ & 0.15 \\
$\quad$ SBP <45 mm Hg) & & & \\
Mechanical pacing & $22(24)$ & $25(27)$ & 0.74 \\
Pneumothorax & $3(3)$ & $5(5)$ & 0.72 \\
Chest tube placement & $12(13)$ & $5(5)$ & 0.08 \\
Reintubation & 0 & $1(1)$ & 1.00 \\
Thrombocytopenia & $8(9)$ & $6(7)$ & 0.59 \\
Sepsis, suspected & $3(3)$ & $5(5)$ & 0.72 \\
Sepsis, confirmed & $3(3)$ & 0 & 0.12 \\
Hyperthermia (>38.5 C) & $20(22)$ & $22(24)$ & 0.86 \\
Hypokalemia (<3.0 mEq/L) & $65(72)$ & $56(61)$ & 0.12 \\
Hypocalcemia (Ca <7.0, & $52(58)$ & $40(43)$ & 0.056 \\
$\quad$ ionized Ca <0.9) & & & \\
Hypoglycemia (glucose & $2(2)$ & $3(3)$ & 1.00 \\
$\quad<45$ mg/d) & & & \\
Hyperglycemia (glucose & $52(58)$ & $47(51)$ & 0.38 \\
$\quad>150$ mg/dl) & & & \\
Acidosis (pH <7.25) & $5(6)$ & $1(1)$ & 0.12 \\
Alkalosis (pH >7.6) & $14(16)$ & $16(17)$ & 0.84 \\
Coagulopathy (PT/PTT >2 & $8(9)$ & $2(2)$ & 0.056 \\
$\quad \times$ control) & $12(13)$ & $11(12)$ & 0.83 \\
Delayed sternal closure & & & \\
\hline
\end{tabular}

${ }^{*}$ Fisher's exact $\mathrm{p}$ value for the effect of treatment.

$S B P$, Systolic blood pressure; $P T$, prothrombin time; $P T T$, partial thromboplastin time.

Alternative explanations for the protection offered by $\mathrm{pH}$-stat in infants may be found in recent experimental studies that suggest that extracellular acidosis may inhibit cerebral excitotoxicity. ${ }^{15,16}$ Furthermore, at deep hypothermia, carbon dioxide appears to exert a direct suppressive effect on cerebral metabolic rate of oxygen, independent of its effects on cerebral blood flow. ${ }^{17}$ Finally, in a recent study in rodents, higher intraischemic carbon dioxide levels appeared to be neuroprotective. ${ }^{18}$

In our study, mean arterial pressures were lower throughout most of cardiopulmonary bypass in the $\mathrm{pH}$-stat group, compared with those managed with alpha-stat, with the most pronounced differences occurring from just before the onset of circulatory arrest through rewarming to $32^{\circ} \mathrm{C}$. The most likely mechanism for lower perfusion pressure in the $\mathrm{pH}$-stat group is vasodilation resulting from hypercarbia. The greater cerebral blood flow among infants in the $\mathrm{pH}$-stat group may have improved cerebral protection by more homogeneous brain cooling or by lowering cerebral temperature slightly. ${ }^{19,20}$ Indeed, in our study, mean coldest tympanic temperature was lower in the $\mathrm{pH}$-stat group.
Table VI. Postoperative neurologic outcomes according to treatment group

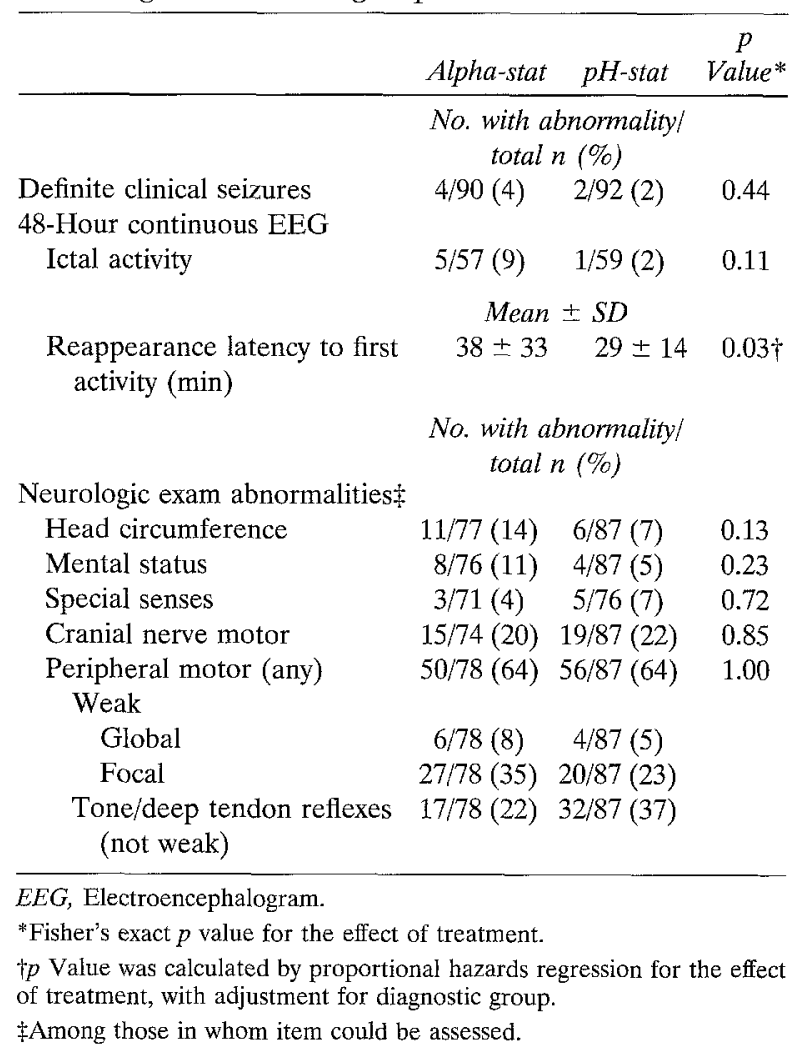

Use of the alpha-stat strategy was associated with a twofold increase in the incidence of EEG seizures in the combined diagnosis groups and a threefold increase within the D-TGA subgroup; however, the low frequency of seizures proscribed sufficient power to detect a statistically significant difference. The infrequency of seizures in our study population may reflect the shorter mean duration of circulatory arrest than in earlier retrospective studies ${ }^{9,10}$ in which alpha-stat management was used. Infants in the $\mathrm{pH}$-stat group recovered first EEG activity more rapidly after rewarming than those in the alpha-stat group. Thus the present study suggests that the $\mathrm{pH}$-stat strategy may be beneficial even with relatively short circulatory arrest periods.

Experimental data in animals support our finding of improved hemodynamic status and postoperative course in infants managed with the $\mathrm{pH}$-stat strategy. Hypercarbic acidotic reperfusion after cardioplegic ischemia in neonatal lambs has been associated with improved recovery of systolic ventricular function and coronary blood flow. ${ }^{21}$ The mechanism by which hypercarbic acidosis could be beneficial during reperfusion is unknown. The effect of hydrogen ion 
concentration on $\mathrm{Na}^{+}-\mathrm{Ca}^{+}$exchange ${ }^{22}$ and on calcium binding to cellular and intracellular $\operatorname{sites}^{23}$ could decrease uptake of potentially lethal calcium by ischemic cells during reperfusion. ${ }^{22,24,25}$ Alternatively, the potent effect of elevated carbon dioxide tension in producing coronary vasodilation may be beneficial during early reperfusion. ${ }^{26-28}$

In conclusion, these data contradict the widely held notion that alpha-stat management is more physiologic and protective during hypothermic cardiopulmonary bypass in infants. Indeed, the current study suggests that the $\mathrm{pH}$-stat management may enhance systemic and cerebral protection during repair of congenital heart lesions in infants in whom deep hypothermic cardiopulmonary bypass is used with or without circulatory arrest. However, management with the $\mathrm{pH}$-stat strategy may be more complex and may require a period of training for perfusionists who are unfamiliar with this technique. Delineation of the longer-term effects of these $\mathrm{pH}$ management strategies awaits follow-up of this population.

We are indebted to our perfusionists, Willis G. Gieser, CCP, Robert A. LaPierre, BS, CCP, Robert J. Howe, BS, $\mathrm{CCP}$, and Bettina Archilla, BS, CCP; to the nursing staff for assistance with adherence to the protocol; to Ludmila Kyn for database and statistical programming; to Donna M. Donati and Donna M. Duva for data management; and to Kathleen M. O'Brien for project coordination.

\section{REFERENCES}

1. Kern F, Greeley W. Pro: pH-stat management of blood gases is not preferable to alpha-stat in patients undergoing brain cooling for cardiac surgery. J Cardiothorac Vasc Anesth 1995;9:215-8.

2. Burrows F. Con: pH-stat management of blood gases is preferable to alpha-stat in patients undergoing brain cooling for cardiac surgery. J Cardiothorac Vasc Anesth 1995;9:21921.

3. Watanabe T, Miura M, Inui K, et al. Blood and brain tissue gaseous strategy for profoundly hypothermic total circulatory arrest. J Thorac Cardiovasc Surg 1991;102:497-504.

4. Murkin JM, Farrar JK, Tween WA, McKenzie FN, Guiraudon GM, Guiraudon G. Cerebral autoregulation and flowmetabolism coupling during hypothermic cardiopulmonary bypass: the influence of $\mathrm{PaCO}_{2}$. Anesth Analg 1987;66:825-32.

5. Greeley WJ, Ungerleider RM, Kern FH, Brusino FG, Smith $R$, Reves JG. Effects of cardiopulmonary bypass on cerebral blood flow in neonates, infants and children. Circulation 1989;80(Suppl):I209-15.

6. Patel RL, Turtle MR, Chambers DJ, James DN, Newman S, Venn GE. Alpha-stat acid-base regulation during cardiopulmonary bypass improves neuropsychologic outcome in patients undergoing coronary artery bypass grafting. $J$ Thorac Cardiovase Surg 1996;111:1267-79.

7. Stephan H, Weyland A, Kazmaier S, Henze T, Menck S,
Sonntag H. Acid-base management during hypothermic cardiopulmonary bypass does not affect cerebral metabolism but does affect blood flow and neurological outcome. $\mathrm{Br} \mathbf{J}$ Anaesth 1992;69:51-7.

8. Murkin JM, Martzke JS, Buchan AM, Bentley C, Wong CA. A randomized study of the influence of perfusion technique and $\mathrm{pH}$ management strategy in 316 patients undergoing coronary artery bypass surgery. II. Neurologic and cognitive outcomes. J Thorac Cardiovasc Surg 1995;110:349-62.

9. Jonas RA, Bellinger DC, Rappaport LA, et al. Relation of $\mathrm{pH}$ strategy and developmental outcome after hypothermic circulatory arrest. J Thorac Cardiovasc Surg 1993;106:362-8.

10. Wong PC, Barlow CF, Hickey PR, et al. Factors associated with choreoathetosis after cardiopulmonary bypass in children with congenital heart disease. Circulation 1992; 86(Suppl):II118-26.

11. Aoki M, Nomura F, Stromski ME, et al. Effects of $\mathrm{pH}$ on brain energetics after hypothermic circulatory arrest. Ann Thorac Surg 1993;55:1093-103.

12. Hiramatsu T, Miura T, Forbess JM, et al. pH strategy and cerebral energetics before and after circulatory arrest. J Thorac Cardiovasc Surg 1995;109:948-58.

13. Skaryak L, Chai P, Kern F, Greeley W, Ungerleider R. Blood gas management and degree of cooling: effects on cerebral metabolism before and after circulatory arrest. $\mathfrak{J}$ Thorac Cardiovase Surg 1995;110:1649-57.

14. Bashein G, Townes BD, Nessly ML, et al. A randomized study of carbon dioxide management during hypothermic cardiovascular bypass. Anesthesia 1990;72:3-6.

15. Kaku D, Giffard R, Choi D. Neuroprotective effects of glutamate antagonists and extracellular acidity. Science 1993; 260:1516-8.

16. Tombaugh G, Sapolsky R. Evolving concepts about the role of acidosis in ischemic neuropathology. J Neurochem 1993; 61:793-803.

17. Hindman B, Dexter F, Cutkomp J, Smith T. pH stat management reduces the cerebral metabolic rate for oxygen during profound hypothermia $\left(17^{\circ} \mathrm{C}\right)$. Anesthesia 1995;82: 983-95.

18. Vannucci R, Towfighi J, Heitjan D, Brucklacher R. Carbon dioxide protects the perinatal brain from hypoxic-ischemic damage: an experimental study in the immature rat. Pediatrics 1995;95:868-74.

19. Busto R, Globus M, Dietrich W, et al. Effect of mild hypothermia on ischemia-induced release of neurotransmitters and free fatty acids in rat brain. Stroke 1989;20:904-10.

20. Dietrich W, Busto R, Alonso O, Globus MT, Ginsberg M. Intraischemic but not postischemic brain hypothermia protects chronically following global forebrain ischemia in rats. $\mathbf{J}$ Cereb Blood Flow Metab 1993;13:541-9.

21. Nomura F, Aoki M, Forbess JM, Mayer JE Jr. Effects of hypercarbic acidotic reperfusion on recovery of myocardial function after cardioplegic ischemia in neonatal lambs. Circulation 1994;90(Suppl):II321-7.

22. Philipson KD, Bersohn NM, Nishimoto AY. Effects of $\mathrm{pH}$ on $\mathrm{Na}-\mathrm{Ca}$ exchange in canine cardiac sarcolemmal vesicles. Circ Res 1982;50:287-93.

23. Langer GA. The effect of $\mathrm{pH}$ on cellular and membrane calcium binding and contraction of myocardium. Circ Res 1985;57:374-82.

24. Nayler WG, Panagiotopoulos S, Elz JS, Daly MJ. Calcium- 
mediated damage during postischaemic reperfusion. J Mol Cell Cardiol 1988;20:II41-54.

25. Elton D, Billingsley AM, Laks $\mathrm{H}$, Chang $\mathrm{P}$. Effect of $\mathrm{PCO}_{2}-$ adjusted $\mathrm{pH}$ on the neonatal heart during hypothermic perfusion and ischemia. J Thorac Cardiovasc Surg 1990;100: 902-9.

26. Nomura F, Aoki M, Mayer JE Jr. Effect of adenosine infusion during reperfusion after cold cardioplegic ischemia in neonatal lambs. Circulation 1993;88(Supp1):II380-6.

27. Kawata $H$, Aoki M, Mayer JE Jr. Nitroglycerin improves functional recovery of neonatal lamb hearts after 2 hours of cold ischemia. Circulation 1993;88(Suppl):II366-71.

28. Fujiwara T, Kurtts TA, Anderson WA, Mayer JE Jr. Highpressure reperfusion injury in neonatal hearts. Surg Forum 1987;38:231-3.

\section{Discussion}

Dr. Julie A. Swain (Lexington, Ky.). Once again Dr. Jonas and his group have given us a study that will be the gold standard. I can only hope, as an adult cardiac surgeon, that my colleagues perform as elegant a clinical study on some of the things that we have been hearing this week about minimally invasive surgery. The Harvard group has taken a clinical observation of choreoathetosis, gone back and done a retrospective study, followed that by very careful laboratory data, and then conducted this excellent prospective study.

The change to the alpha-stat technique occurred rather precipitously in adult and pediatric cardiac surgery in the early $1980 \mathrm{~s}$, and I feel somewhat responsible for that because of some of our early data. I think it has worked out well in the adult group, but now we find that it probably was not an appropriate change in the pediatric group.

The problem with this study is that despite a very large long-term study (4 years and almost 200 patients), there are very few items that were significantly different, that is, $p<0.05$; essentially the absence of seizure activity, the intensive care unit stay, things of that sort. However, one cannot ignore the overwhelming trends in virtually everything looked at, from neurologic status to metabolic status to chest tube placement, and I think that we have to use our clinical judgment rather than be captive to statistics.

I have a couple of questions. During either alpha-stat or $\mathrm{pH}$-stat regulation the intracellular $\mathrm{pH}$ is defended along the alpha-stat regulation, so we are looking at extracellular $\mathrm{pH}$ changes only. Do you find a reason to modify your strategy even more with a short period of alpha-stat perfusion before going to either circulatory arrest or low flow? Second, I could not determine how many of each group had circulatory arrest versus low-flow bypass, knowing, of course, that there appears to be a great deal of difference between those two techniques.

Finally, in your D-TGA group, between IVSs and VSDs, there appeared to be a fair difference in the numbers undergoing alpha-stat and $\mathrm{pH}$-stat strategy. Would a subgroup analysis of TGA with VSDs show any differences in your results?

Dr. Bradley S. Allen (Chicago, Ill.). During your presentation, I was struck by something I was not aware of, which is that your oxygen levels were lower in the $\mathrm{pH}$-stat group. We have done some studies in cyanotic children and found that higher oxygen levels on bypass can result in an unintended injury, which we and others have referred to as the "reoxygenation injury." In addition, a recent study from this Journal demonstrated that even an oxygen tension of $180 \mathrm{~mm} \mathrm{Hg}$ can decrease tissue perfusion during routine bypass. I am therefore wondering what the differences in the oxygen concentrations were between the two groups, and whether the change in perfusion is due to differences in oxygen levels rather than $\mathrm{pH}$ management.

Dr. Jonas. I would like to thank the discussants for their comments and questions.

Dr. Swain, I think this study overall was really much less sensitive than it could have otherwise been because we reduced the circulatory arrest time to only 20 minutes. In our previous retrospective studies and in the prospective randomized comparison of circulatory arrest and low-flow bypass, we had used up to an hour or more of circulatory arrest. Perhaps if we had conducted this study with 1 hour of circulatory arrest it is more likely that we would have demonstrated more significant differences between the two groups.

We have pondered the issue of cooling with the pH-stat strategy and then changing to the alpha-stat strategy immediately before the circulatory arrest phase. We considered adding that as a third arm of the study. When Frank Kern was with us from Duke we talked about this a lot. Frank subsequently went back to Duke and did a laboratory study looking at this, which suggested that that might indeed be a preferable approach. It certainly is something that still intrigues me, though I do not know whether we are going to be able to have the resources to organize such a study. On the other hand, you can also argue that there are theoretical reasons why it might be better to stay with the pH-stat strategy until the end of cooling. Much of the injury is related to calcium ion influx into cells. If the level of protons is higher, that is, a lower $\mathrm{pH}$ in the extracellular milieu, then the theory is that there is less calcium influx. There is more competition with calcium ions and, hence, less reperfusion injury at the time of reperfusion.

The majority of patients did have some circulatory arrest. For example, our D-TGA population all had balloon atrial septostomies, and so they all required a brief circulatory arrest time for closure of that atrial septal defect. Those with an atrial septal defect plus a VSD required longer circulatory arrest times. In patients with TOF, for example, my own practice is to use a single venous cannula still and to do much of that operation on low-flow bypass, but perhaps to arrest for 15 or 20 minutes while I do the posterior and inferior corner of the VSD closure. Overall, the circulatory arrest time was only 20 minutes, mean, for the total population.

Regarding your observation about the number of patients within the IVS versus the VSD subgroup, I think that is a very interesting observation. So far as I know, we have not undertaken a subgroup analysis within the D-TGA subgroup. We had already divided the overall population into subgroup analyses of each anatomic diagnosis. I will ask our statistician to undertake that analysis and see if that makes any difference in the transposition result. Certainly when I first saw the transposition result it immediately occurred to me that this was the group that 
had the longest overall ischemic time, that is, whole-body ischemia as well as myocardial ischemia, and that the strongest result in terms of statistical significance would be seen in this population.

Regarding Dr. Allen's questions, the lower oxygen tension on bypass is related to the Bohr effect, that is, the affinity of oxygen and hemoglobin varies according to $\mathrm{pH}$. The difference is quite a small one, but it was consistent, and that was why we came up with a statistically significant difference between the two groups. I do not believe that the level of oxygenation would have been sufficiently different between the groups to make any difference in terms of reoxygenation injury. The reason I say that is because we continue to use $100 \%$ oxygen. I suspect that we are one of the few groups in the country that has not gone to using air. Therefore our oxygen tensions on bypass are all very high, usually 400 to $500 \mathrm{~mm} \mathrm{Hg}$. The differences between groups were perhaps 30 or $40 \mathrm{~mm} \mathrm{Hg}$. It is not clear to me that reoxygenation injury is a real event in this population. In fact, we suspect that there may be disadvantages in terms of nitrogen microemboli if you introduce nitrogen into the oxygenator. We are looking at exactly this question in our laboratory model right now, and the early results suggest that we are not going to see any advantage in using nitrogen in our gas mixture. In conclusion, I do not believe that the differences in outcome are related to reoxygenation injury.

Dr. Frank L. Hanley (San Francisco, Calif.). Dr. Jonas, you speculated in your responses to Dr. Swain that if the patients had had longer periods of circulatory arrest, you may have seen greater changes. Would you care to speculate in the other direction? If you had avoided circulatory arrest completely in these patients, do you think that you would see less or no trends in this direction? I noted from your entire patient population that none of those patients mandated circulatory arrest. In my own practice I would not have used circulatory arrest in any of those patients.

I have one other very brief comment. The other secondary change as a result of the $\mathrm{pH}$-stat/alpha-stat difference was the difference in reperfusion pressure that you mentioned. How great was that reperfusion pressure difference in the two groups and do you think that potentially would have any effect on the outcomes?

Dr. Jonas. Thank you, Dr. Hanley. With respect to circulatory arrest times, in our previous study we were not able to demonstrate deleterious effects under about 30 minutes. In that previous study, there were no patients who had a seizure if their circulatory arrest time was less than 35 minutes. I think the issue is not just circulatory arrest. Other important issues include the following: What hematocrit values and flow rates are you using? Remember that these things interact. Most of the deleterious effects that we saw with our online monitoring in the laboratory were in parameters such as the cytochrome level with near-infrared spectroscopy. The cytochrome levels suggested that much of the injury occurs during the early phase on bypass when the brain is still warm and the blood being introduced is cold, dilute, and alkaline. It will depend, I believe, on what hematocrit levels and what flow levels are being used as to how much of a hypoxic insult is being caused during the early phases of cooling. That, then, potentially sets you up for an injury during the circulatory arrest time. It does not prepare you as well for the circulatory arrest period if you introduce that injury beforehand. I think the question should be rephrased to ask if it would make a difference if you used a hematocrit of 40 to have $\mathrm{pH}$-stat versus alpha-stat, for example, or would it make a difference if you used a flow index of $3 \mathrm{~L}$ versus $1.5 \mathrm{~L}$, for example.

Regarding the actual differences in perfusion pressure, I cannot supply the exact numbers, but the differences were relatively subtle. I believe the difference in perfusion pressure was probably no more than about $10 \%$. The pressures were lower with $\mathrm{pH}$-stat relative to alpha-stat, and yet the result was an improved outcome with $\mathrm{pH}$-stat. When I have presented some of this work in a preliminary fashion to groups performing adult cardiac surgery, of course their concern is that this would result in a steal away from watershed areas beyond vascular stenosis. I think that is a very real problem for their patients, but I do not believe in the infant population that pressure has an important role in the outcome.

\section{Bound volumes available to subscribers}

Bound volumes of The Journal of Thoracic and Cardiovascular Surgery are available to subscribers (only) for the 1997 issues from the Publisher, at a cost of $\$ 110.50$ for domestic, $\$ 139.64$ for Canadian, and $\$ 130.50$ for international subscribers for Vol. 113 (January-June) and Vol. 114 (July-December). Shipping charges are included. Each bound volume contains a subject and author index and all advertising is removed. Copies are shipped within 60 days after publication of the last issue of the volume. The binding is durable buckram with the Journal name, volume number, and year stamped in gold on the spine. Payment must accompany all orders. Contact Mosby-Year Book, Inc., Subscription Services, 11830 Westline Industrial Drive, St. Louis, Missouri 63146-3318, USA; phone $800-453-4351$ or 314-453-4351.

Subscriptions must be in force to qualify. Bound volumes are not available in place of a regular Journal subscription. 